\title{
Ant Diversity (Hymenoptera: Formicidae: Myrmicinae) in Three Housing Types in Bandar Lampung
}

\author{
`Ahmad Fauzi Rosnadi, Dwijowati Asih Saputri, Marlina Kamelia \\ Jurusan Pendidikan Biologi Fakultas Tarbiyah dan Keguruan Universitas Islam Negeri Raden Intan Lampung \\ Jl. Letkol. H. Endro Suratmin Sukarame, Bandar Lampung 35131 \\ *ahmadfauzirosnadi@gmail.com
}

\begin{abstract}
Bandar Lampung City has a population of 1.051 .500 people with a density of $3.308,4$ people $/ \mathrm{km}^{2}$ in 2018. The population is densely accompanied by residential developments, one of which is housing. Housing in the city of Bandar Lampung amounted to 220 housing estates in 2018 consisting of types 21, 36, 45.54, and 70. Rapidly increasing development certainly affected the surrounding ecosystem. The ant is one indicator of change in the environment.Therefore it is important to conduct research on identification of Myrmicinae ants in three types of housing in Bandar Lampung City. The research was conducted in November October 2018. This type of research is quantitative with survey methods. Housing of each type is selected by random sampling then ant samples are taken using the standardized transect method. Two transects were installed in the yard of the house and a roadside transect. The ants obtained were identified using photographs, images and the key of determination. The results showed that there were 5 species of Myrmicinae from 3 genera namely Solenopsisgeminata, Solenopsisinvicta, Solenopsismolest, Tetramorium sp., and Monomorium $\mathrm{sp}$. The most dominant subfamily Formicidae habitants are in the house and terrace house.

Keyword: myrmicinae, identification, three types of housing
\end{abstract}

\section{PENDAHULUAN}

Kota Bandar Lampung memiliki kepadatan penduduk mencapai sekitar 3. 308,4 jiwa $/ \mathrm{km}^{2}$ sehingga Kota Bandar Lampung menjadi kota dengan pembangunanyang pesat baik dalam bentuk perumahan elit atau pemukiman sederhana. Pertambahan penduduk selama 4 tahun dari tahun 20102014 sejumlah 285.300 jiwa maka pembangunan perumahan menjadi hal yang penting di Kota Bandar Lampung (BPS Kota Bandar Lampung, 2014). Perumahan dan permukiman merupakan kebutuhan dasar manusia, sebagai tempat berlindung, tempat beristirahat dan wadah untuk aktifitasaktifitas harian manusia seperti mandi, makan dan masak. Perumahan merupakan proses dan tempat permukiman manusia dalam menciptakan tatanan kehidupan untuk bermasyarakat dengan lingkungan sekitar (Hutagalung, 1994). Secara umum kota sebagai pusat permukiman mempunyai peran penting dalam memberi pelayanan di berbagai bidang kehidupan bagi penduduknya dan daerah sekitarnya (Badan Pertahanan Nasional, 2015).

Perumahan pada dasarnya dapat dibagi menjadi beberapa tipe. Berdasarkan ukurannya perumahan dapat dibedakan menjadi tipe 21, 36, 45, 54, 70. Penggolongan tipe perumahan ini sesuai dengan luas rumah tersebut. Dari pembangunan yang berkembang dan bertambah, berdampak pada ketersediaan lahan hijau yang semakin sempit dan eksploitasi lahan yang berlebihan mengakibatkan rusaknya tatanan ekosistem pada lingkungan sekitar. Jumlah penduduk yang bertambah banyak membuat pengembang perumahan (developer) membangun perumahan di Kota Bandar Lampung. Perumahan dibangun sesuai 
dengan peraturan daerah nomor 4 tahun 2012 kota Bandar Lampung (Dinas Perumahan dan Pemukiman, 2015). Pembangunan perumahan seharusnya berada di daerah yang datar akan tetapi dengan semakin berkurangnya lahan terutama di perkotaan, lahan yang landai ataupun curam dijadikan tempat bermukim. Sesuai dengan pernyataan Sumaatmadja dalam Latumahina dan Ismanto (2018) bahwa mula-mula manusia memilih ruang geografinya untuk permukimannya di wilayah-wilayah yang sesuai dengan kebutuhan yang menjamin kehidupannya (habitable). Tetapi akibat pertumbuhan penduduk terus meningkat, daerah-daerah yang tidak habitable-pun dijadikan tempat tinggal mereka.

Distribusi semut banyak ditemukan pada daerah tropis dan sub tropis yang dilakukan dibeberapa bagian Asia. Semut berkembang di sebagian besar ekosistem, dan dapat membentuk $15-25 \%$ dari biomassa hewan terestrial. Kisaran suhu antara $25^{\circ} \mathrm{C}-32^{\circ} \mathrm{C}$ merupakan suhu optimal dan toleran bagi aktifitas semut di daerah tropis. Pendapat ini didukung oleh penelitian tentang mesofauna oleh Hadi dan Sugiarto (2007) yang menyatakan kelimpahan semut relatif tinggi sehingga hampir dipastikan bahwa di sekitar kita pasti ada semut. Selain itu semut mudah ditemukan karena makanannya yang melimpah disekitar kita. Sumber makanan semut sangat beranekaragam antara lain sisa makanan yang kita buang, hewan yang mati, tumbuhan atau hewan lain.

Semut (Hymenoptera: Formicidae) termasuk ke dalam kelompok serangga yang keanekaragamannya sangat tinggi. Habitat yang ditempatinya bervariasi, mulai dari padang pasir, savana, hutan hujan tropis, sampai pada area yang dihuni manusia. Keberadaannya yang melimpah di alam tidak terlepas dari pengaruh ketersediaan makanan dan kesesuaiannya dengan kondisi lingkungan. Beberapa spesies semut Subfamili Myrmicinae mampu memanfaatkan terjadinya peningkatan suhu melalui peningkatan aktivitas dan jumlah koloni, yang menyebabkan perubahan struktur komunitas melalui mekanisme kompetisi. Keberadaan tempat bersarang yang sesuai juga memengaruhi keberadaan semut subfamili Myrmicinae. Sebagai contoh, perkakas rumah tangga dan makanan yang tersimpan di rumah menjadikan habitat yang sesuai untuk tempat bersarang dan mencari makan bagi semut (Hasriyanty, dkk, 2015). Berdasarkan uraian di atas, terlihat bahwa Subfamili Myrmicinae yang paling banyak tersebar di area dalam gedung, dan banyak membangun sarang didekat permukiman manusia sehingga peneliti tertarik untuk meneliti tentang identifikasi semut Subfamili Myrmicinae di area perumahan Kota Bandar Lampung, di tiga tipe perumahan 36, 45 dan 54 karena ketiga tipe perumahan ini memiliki perbedaan kondisi lingkungan seperti ketinggian, suhu, serta kelembababan sehingga mempengaruhi persebaran semut famili Myrmicinae.

\section{METODE}

Jenis penelitian ini merupakan deskriptif kualitatif dengan menceritakan terhadap hasil temuan semut pada perumahan di Bandar Lampung yang telah terpilih. Menentukan lokasi sampel menggunakan cara random sampling/acak sempel. Menggunakan teknik Random Sampling, dikarenakan kondisi dan populasi. Pengambilan sampel dibuat dengan metode transek sampling.

Transek sampling merupakan cara paling efektif memudahkan pengambilan data. Setiap transek $8 \times 1 \mathrm{~m}$ dipilih 2 lokasi pencuplikan (plot) dengan ukuran 1 x $1 \mathrm{~m}$ pada lokasi pekarangan rumah dan tepi jalan yang terbagi dalam 3 tipe perumahan. Pada setiap tipe perumahan dipilih secara acak tiga perumahan yang berbeda lokasi karena kondisi tempat yang berbeda diduga memiliki keragaman semut yang berbeda pula. Pada tiap-tiap perumahan di bagi dua titik lokasi atau 2 transek. Setiap transek sampling terdapat 8 plot pengambilan sampel. Penelitian ini memiliki tahapan kerja sebagai berikut: 
1. Tahap Persiapan: Tahap awal pelaksanaan peneliti memilih beberapa wilayah yang akan di ambilperumahan kota Bandar Lampung. Menentukan lokasi sampel dengan teknik random sampling selanjutnya mengumpulkan sampel semut yang ditemukan di lokasi dengan teknik direct sempling pada transek sampling yang telah dipasang.

2. Tahap Pelaksanaan: Penelitian ini selanjutnya masuk pada tahapan pelaksanaan yang digunakan untuk menemukan lokasi sampel semut padaperumahan tipe 36 , tipe 45 , dan tipe 54, setiap lokasi di tentukan menggunakan teknik random sampling, dalam cara ini terlebih menemukan lokasi pengambilan sempel selanjutnya mengumpulkan data terkait perumahan yang ada di kota Bandar Lampung, Ialu membagi menjadi tiga tipe perumahan. Transek di pasang dan memeriksa semua bagian yang ada di dalam transek. Setiap perumahan mendapatkan 2 transek sampling untuk diamati yakni di bagian tepi jalan mewakili (seperti: tepi jalan utama, pinggir gorong-gorong) dan halaman rumah (seperti: teras atau belakang rumah, halaman depan rumah, tepi dinding rumah) (Apriyanto, dkk., 2014). Sampel yang telah ditemukan selanjutnya dimasukkan ke dalam botol sampel yang berisi alkohol $70 \%$ dan telah diberi kertas label, kertas label bertuliskan tipe perumahan dan plot pengambilan sampel. Botol sempel berisi alkohol 70\% bertujuan menjaga tubuh semut agar tetap utuh saat diidentifikasi.

3. Tahap Akhir Penelitian: Pada tahap akhir dari penelitian ini ialah dengan mencocokan dan mengamati hasil gambar penelitian dengan buku kunci determinasi (Hashimoto, 2003). Penelitian ini dilanjutkan dengan analisis data yang diperoleh. Analisis data dalam penelitian ini yakni perhitungan keanekaragaman

$\left(H^{\prime}\right)$ dan indeks keseragaman $(E)$ :

1) Indeks Keanekaragaman ( $\left.\mathrm{H}^{\prime}\right)$ Mendeskripsikan serta menganalisis data jumlah individu masing-masing jenis pada suatu komunitas. Keanekaragaman dihitung dengan rumus indeks Shannon-Winner (Odum, 1993):

$$
\mathrm{H}^{\prime}=-\sum_{t=1}^{S} \mathrm{Pi} \text { In Pi }
$$

$$
\begin{aligned}
& \text { Dengan: } \\
& \mathrm{H}=\text { Indeks } \\
& \text { keanekaragaman } \\
& \text { Shannon-Wiener } \\
& \mathrm{Pi} \quad=\sum n \mathrm{ni} / \mathrm{N} \\
& \mathrm{ni} \quad=\text { Jumlah individu spesies } \\
& \text { ke-i } \\
& \mathrm{N} \quad=\text { Jumlah total individu } \\
& \mathrm{S} \quad=\text { Jumlah Genera }
\end{aligned}
$$

Kriteria nilai indeks keanekaragaman Shannon - Wiener $\left(\mathrm{H}^{\prime}\right)$ adalah sebagai berikut:

$$
\begin{array}{ll}
\mathrm{H}^{\prime}<1= & \text { komunitas rendah (Tidak } \\
& \text { Stabil) } \\
1<\mathrm{H}^{\prime}= & \begin{array}{l}
\text { komunitas sedang } \\
\text { (Kestabilannya Sedang) }
\end{array} \\
\leq 3 & \text { komunitas tinggi (Stabil) }
\end{array}
$$

2) Indeks Kemerataan

Untuk mengetahui besarnya indeks kemerataan menurut Pielou (1966) dalam Odum (1993) yaitu sebagai berikut:

$$
\mathrm{E}=\frac{H^{\prime}}{\log S}
$$

\section{Dengan:}

$\mathrm{E}=$ Indeks kemerataan

$\mathrm{H}^{\prime}=$ Indeks KeanekaragamanShannon

$\mathrm{S}=$ Jumlah spesies

Kriteria nilai indeks berada diantara 0-1 menurut Pielou (1966) dalam Odum (1993):
$0<\mathrm{E} \leq 0,5$
$=$ Komunitas tertekan
$0,5<\mathrm{E} \leq 0,75=$ Komunitas labil
$0,75<\mathrm{E} \leq 1 \quad=$ Komunitas stabil 


\section{HASIL DAN PEMBAHASAN}

Sampel semut pada tiga tipe penelitian ini hanya mengidentifikasi subfamili Myrmicinae pada tiga tipe perumahan yang ada di
Bandar Lampung. Penelitian ini dilakukan pada 9 perumahan dengan 3 tipe perumahan. apat dilihat pada Tabel 1 .

Tabel 1. Sebaran Semut Subfamili Myrmicinae Pada Tiga Tipe Perumahan

\begin{tabular}{|c|c|c|c|c|c|}
\hline $\begin{array}{l}\text { Lokasi } \\
\text { penelitian }\end{array}$ & $\begin{array}{c}\text { Nama } \\
\text { Perumahan }\end{array}$ & Subfamili & Genus & $\begin{array}{l}\text { Spesies semut yang } \\
\text { ditemukan }\end{array}$ & Jumlah \\
\hline \multirow{8}{*}{$\begin{array}{l}\text { Perumahan } \\
\text { tipe } 36\end{array}$} & \multirow{2}{*}{$A$} & \multirow{2}{*}{\multicolumn{2}{|c|}{ Solenopsis }} & Solenopsis invicta & 12 \\
\hline & & & & Solenopsis geminate & 2 \\
\hline & \multirow{4}{*}{ B } & \multirow{6}{*}{ Myrmicinae } & & Solenopsis geminate & 13 \\
\hline & & & Solenopsis & Solenopsis invicta & 6 \\
\hline & & & & Solenopsis molesta & 1 \\
\hline & & & Tetramorium & Tetramorium bicarinatum & 1 \\
\hline & \multirow{2}{*}{ C } & & Solenopsis & Solenopsis geminate & 10 \\
\hline & & & Monomorium & Monomorium floricola & 7 \\
\hline \multirow{7}{*}{$\begin{array}{l}\text { Perumahan } \\
\text { tipe } 45\end{array}$} & \multirow{3}{*}{ A } & \multirow{7}{*}{ Myrmicinae } & \multirow{2}{*}{ Solenopsis } & Solenopsis geminata & 17 \\
\hline & & & & Solenopsis invicta & 7 \\
\hline & & & Monomorium & Monomorium Floricola & 5 \\
\hline & \multirow{2}{*}{ B } & & \multirow{2}{*}{ Solenopsis } & Solenopsis geminate & 15 \\
\hline & & & & Solenopsis geminate & 8 \\
\hline & \multirow{2}{*}{$\mathrm{C}$} & & \multirow{2}{*}{ Solenopsis } & Solenopsis invicta & 23 \\
\hline & & & & Solenopsis geminate & 17 \\
\hline \multirow{10}{*}{$\begin{array}{l}\text { Perumahan } \\
\text { Tipe } 54\end{array}$} & \multirow{4}{*}{ A } & \multirow{10}{*}{ Myrmicinae } & \multirow{2}{*}{ Solenopsis } & Solenopsis invicta & 12 \\
\hline & & & & Solenopsis molesta & 15 \\
\hline & & & \multirow{2}{*}{ Monomorium } & Solenopsis geminate & 12 \\
\hline & & & & Monomorium floricola & 15 \\
\hline & \multirow{3}{*}{ B } & & \multirow{2}{*}{ Solenopsis } & Solenopsis geminate & 18 \\
\hline & & & & Solenopsis molesta & 10 \\
\hline & & & Tetramorium & Tetramorium bicarinatum & 14 \\
\hline & \multirow{3}{*}{ C } & & Solenopsis & Solenopsis invicta & 15 \\
\hline & & & Tetramorium & Tetramorium bicarinatum & 7 \\
\hline & & & Monomorium & Monomorium floricola & 9 \\
\hline Total Individu & & & & & 270 \\
\hline Total Genus & & & & & 3 \\
\hline Total Spesies & & & & & 5 \\
\hline
\end{tabular}

Berdasarkan gambar dan tabel diatas merupakan menunjukan jenis semut subfamili Myrmicinae yang diperoleh dari ke sembilan perumahan dengan tiga tipe perumahan di Bandar Lampung adalah
Solenopsis geminata, Solenopsis invicta, Solenopsis molesta, Monomorium sp., Tetramorium sp. Berikut adalah gambar hasil identifikasi: 


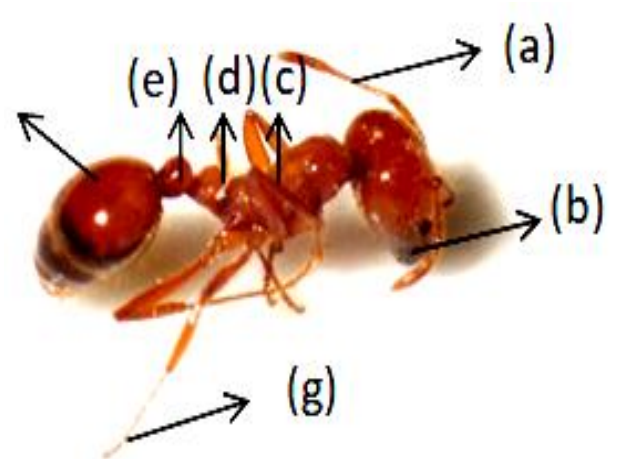

Gambar1. SemutSolenopsis geminate Ket. a. Antena, b. Mata, c.Mesosoma,d.Petiole, e. Postpotiole, f. Gaster, g.Legs

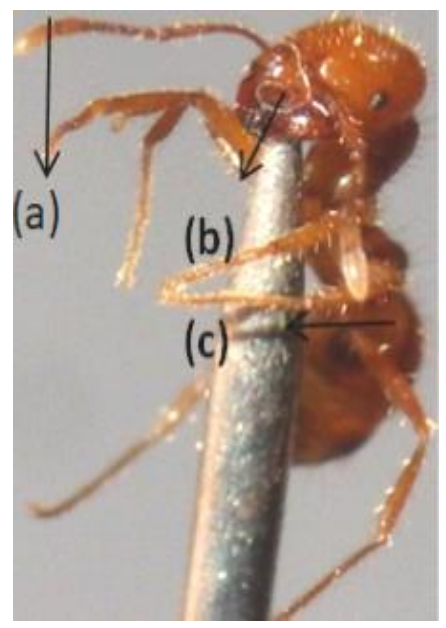

Gambar 2. Semut Solenopsis invicta Ket. a. Antena, b. Mandible, c. Legs

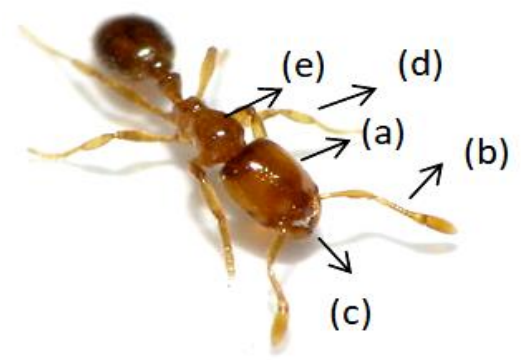

Gambar 3. Semut Solenopsis molesta Ket. a. Kepala, b. Antena, c. Mandible, d. Legs, e. Mesosoma

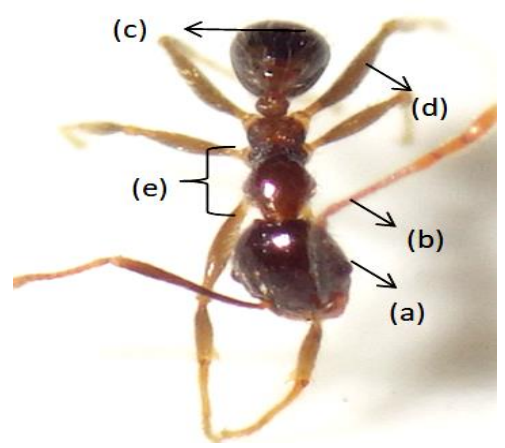

Gambar 4. Semut Monomorium sp. Ket. a. Mata, b. Antena, c. Gaster, d. Legs, e. Alitrunk

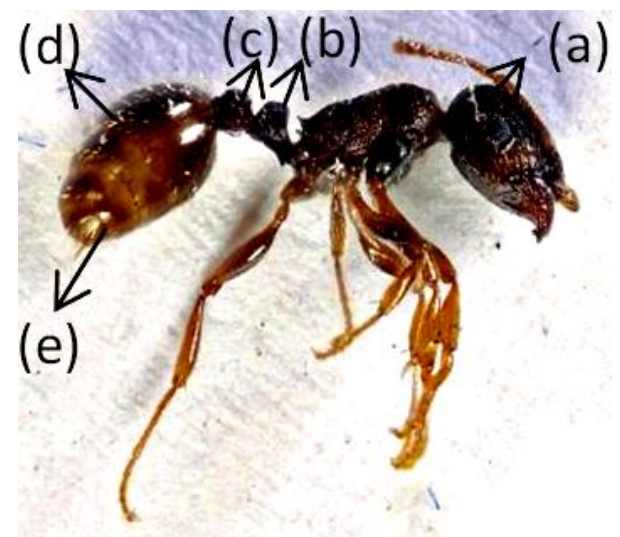

Gambar 5. Semut Tetramorium sp. Ket. a. Mata, b. Petiole, c. Postpetiole, d. Gaster e.String

Hasil identifikasi selanjutnya digunakan untuk menghitung jumlah total per individu yang didapatkan. Jumlah total per individu yang didapatkan kemudian digunakan untuk menghitung indeks keanekaragaman Shannon-Winner dan juga indeks kemerataan.

Data dihitung berdasarkan jenis perumahan yaitu tipe 36, 45, serta 54. Data hasil perhitungan indeks keanekaragaman dan kemerataan semut sub famili Myrmicinae ditampilkan pada tabel berikut ini: 
Tabel 2. Indeks keanekaragaman dan kemerataan subfamili Myrmicinae Perumahan Tipe 36

\begin{tabular}{llccccc}
\hline Tipe & \multicolumn{1}{c}{ Spesies } & Jumlah & $\mathrm{Pi}$ & In pi & pi In pi & Ket \\
\hline 36 & Solenopsis invicta & 28 & 0,5 & $-0,69315$ & $-0,34657$ & \\
& Solenopsis geminata & 15 & 0,267857 & $-13,173$ & $-0,35285$ & \\
& Solenopsis molesta & 5 & 0,089286 & $-241,591$ & $-0,21571$ & \\
Monomorium floricola & 1 & 0,017857 & $-402,535$ & $-0,07188$ & \\
& Tetramoium sp. & 7 & 0,125 & $-207,944$ & $-0,25993$ & \\
Jumlah individu & 56 & & & $-124,694$ & \\
H' & & & & 124,694 & Sedang \\
Hmax & & & & $1,609,438$ & \\
E & & & & 0,774768 & Rendah \\
\hline
\end{tabular}

Tabel 3. Indeks keanekaragaman dan kemerataan subfamili Myrmicinae Perumahan Tipe 45

\begin{tabular}{llccccc}
\hline Tipe & \multicolumn{1}{c}{ Spesies } & Jumlah & $\mathrm{Pi}$ & In pi & $\mathrm{pi} \mathrm{In} \mathrm{pi}$ & Ket. \\
\hline 45 & Solenopsis geminate & 57 & 0,655172 & $-0,42286$ & $-0,27704$ & \\
& Solenopsis invicta & 30 & 0,287356 & $-124,703$ & $-0,35834$ & \\
& Monomorium floricola & 5 & 0,057471 & $-285,647$ & $-0,16416$ & \\
Jumlah individu & 92 & & & $-0,79955$ & \\
H' & & & & 0,799552 & Rendah \\
Hmax & & & & $1,098,612$ & \\
E & & & & 0,727783 & Rendah \\
\hline
\end{tabular}

Tabel 4. Indeks keanekaragaman dan kemerataan subfamili Myrmicinae Perumahan Tipe 54

\begin{tabular}{llccccc}
\hline Tipe & \multicolumn{1}{c}{ Spesies } & Jumlah & $\mathrm{Pi}$ & In pi & pi In pi & Ket. \\
\hline 54 & Solenopsis invicta & 30 & 0,23622 & $-144,299$ & $-0,340864$ & \\
& Solenopsis geminata & 27 & 0,212598 & $-154,835$ & $-0,329177$ & \\
& Solenopsis molesta & 25 & 0,19685 & $-162,531$ & $-0,319943$ & \\
& Tetramoium bicarinatum & 24 & 0,188976 & $-166,613$ & $-0,31486$ & \\
Monomorium floricola & 21 & 0,165354 & $-179,966$ & $-0,297582$ & \\
& Jumlah Individu & 127 & & & $-1,602,426$ & \\
H' & & & & $1,602,426$ & Sedang \\
& Hmax & & & & $1,609,438$ & \\
E & & & & 1,00 & Merata \\
\hline
\end{tabular}

\section{Pembahasan}

Indeks keanekaragaman di atas menunjukan adanya tingkat keanekaragaman yang tergolong sedang yaitu terdapat pada perumahan tipe 36 dan 54, pada perumahan tipe 36 memperoleh nilai indeks sebesar 1,24. Sedangkan pada perumahan tipe 54 memperoleh nilai indeks sebesar 1,60. Hal ini dipengaruhi oleh suhu, kelembaban serta ketinggian pada lokasi perumahan tipe 54. Menurut Krebs tingkat keanekaragaman jenis berkaitan dengan jumlah kekayaan jenis dalam suatu lokasi tertentu. Lebih lanjut Magurran menjelaskan bahwa nilai indeks 
keanekaragaman jenis $\left(H^{\prime}\right)$, juga dipengaruhi oleh persebaran kelimpahan jenis di kawasan tersebut. Semakin tinggi nilai $\left(\mathrm{H}^{\prime}\right)$, maka semakin tinggi pula keanekaragaman jenis, produktivitas, tekanan pada ekosistem dan kestabilan ekosistem. Sedangkan tingkat keanekaragaman rendah terdapat pada perumahan tipe 45 dengan nilai indeks 0.8203 .

Indeks Keseragaman (E), Indeks keseragaman pada perumahan tipe 36 dikatakan keseragaman (E) komunitas stabil, artinya jumlah biota pada masing-masing jenis sama tidak jauh berbeda sehingga memperoleh nilai indeks yang didapatkan adalah 0,77 , pada perumahan tipe 45 dikatakan keseragaman komunitas dikatakan labil, artinya kecil indeks keseragaman populasi/komunitas hal ini menunjukan jumlah individu setiap jenis tidak sama sehingga ada jenis yang mendominasi (Yuniar dan Haneda, 2015), nilai indeks yang didapatkan pada perumahan tipe 45 adalah 0,72 , kemudian pada perumahan tipe 54 dikatakan keseragaman komunitas stabil, berbeda 2 perumahan sebelumnya karena nilai indeks yang didapatkan adalah 1,00. Indeks keseragaman tersebut dapat dilihat pada Gambar 6 dibawah ini:

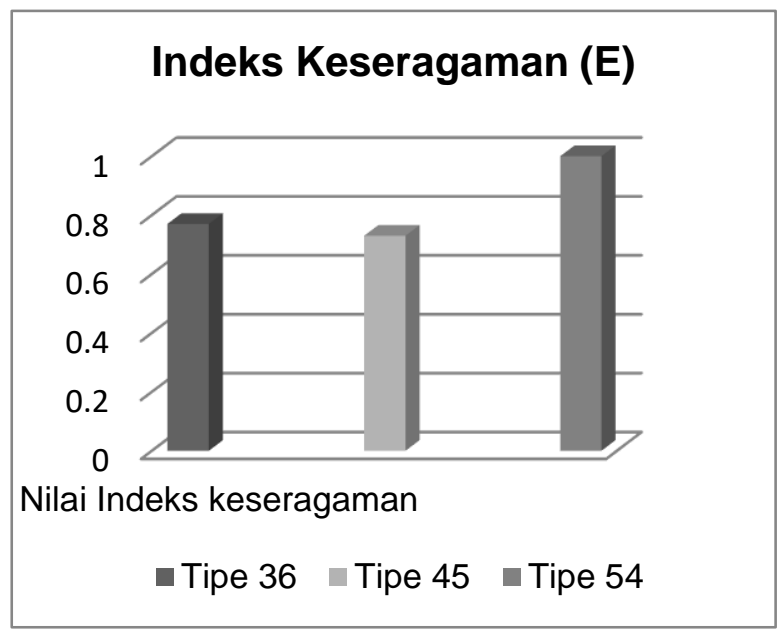

Gambar 6. Indeks Keseragaman (E)

Gambar 6 diatas menunjukan perbedaan yang terlihat dari indeks keragaman pada perumahan tipe 36 diperoleh nilai yaitu 0,77 dengan indeks kemerataan relatif merata hal ini karena keseragaman setiap individu pada komunitasnya stabil merata antara spesies satu dengan yang lain atau jumlah setiap spesies relatif sama.

Sedangkan rumah tipe 45 memperoleh indeks keseragaman (E) yaitu 0,73 kemerataan rendah dibandingkan dengan perumahan tipe 36 dan tipe 54. Hal ini dikarenakan komunitas labil adanya spesies yang mendominasi. Pada perumahan tipe 54 indeks kemerataan (E) menunjukan angka yang stabil untuk komunitas semut yang ditemukan yaitu diperoleh nilai 1,00 memiliki indeks keseragaman yang lebih tinggi.

Hasil dari identifikasi semut subfamili Myrmicinae pada tiga perumahan tipe 36 ditemukan lima spesies yakni Solenopsis geminata, Solenopsis invicta, Solenopsis molesta, Monomorium dan Tetramorium bicarinatum. Sedangkan pada perumahan tipe 45 ditemukan tiga spesies yakni Solenopsis geminata, Solenopsis invicta, Monomorium floricola. Pada perumahan tipe 54 ditemukan lima spesies yang sama dengan perumahan tipe 45 yaitu Solenopsis geminata, Selonopsis invicta, Solenopsis molesta, Monomorium floricola dan Tetramorium bicarinatum.

\section{KESIMPULAN}

Berdasarkan hasil penelitian dan pembahasan menyimpulkan bahwa identifikasi semut subfamili Myrmicinae ditemukan ada 5 spesies dari 3 genus, yakni Solenopsis geminata, Solenopsis invicta, Solenopsis molesta, Monomorium sp, dan Tetramorium. Sebaran semut subfamili Myrmicinae menunjukan bahwa paling banyak sebaran dan relatif merata dari berbagai genus yang termasuk ke dalam subfamili Myrmicinae ialah pada perumahan tipe 54. Semut yang paling banyak ditemukan adalah Solenopsis sp. dan frekuensi yang paling rendah sebarannya adalah Monomorium sp. Perbedaan jenis semut yang ditemukan pada ketiga tipe perumahan dipengaruhi oleh suhu, ketinggian, serta ketersedian makanan.

Adapun saran dari penelitian identifikasi semut Myrmicinae ini ialah perlu adanya 
penelitian lebih lanjut tentang jumlah populasi, tingkat serangan, dan keanekaragaman genus semut pada Perumahan di Kota Bandar Lampung.

\section{REFERENSI}

Apriyanto, Hadi, U. K., Soviana, S. (2014). Keragaman jenis semut pengganggu di permukiman Bogor. Jurnal Kajian Veteriner,3(2), 213-223.

Badan Pertanahan Nasional. (2014). Himpunan Karya Tulis Pendaftaran Tanah.Bandar Lampung, Lampung: Diakses dari https:// Bandar Lampung Kota. bps. go. Id

Dahelmi, H. H. (2015). Inventarisasi semut yang ditemukan pada perkebunan Buah Naga Lubuk Minturun, Kota Padang dan Ketaping, Kabupaten Padang Pariaman, Sumatera Barat.Jurnal Biologi Universitas Andalas 4(1), 57-64. Diakses dari https://jbioua.fmipa.unand.ac.id

Dinas Perumahan dan Permukiman Kota Bandar Lampung. (2015). Data Perumahan 2015. Bandar Lampung.

Hadi, U. P. dan Sugiarto. (2007). Jenis-jenis semut hama permukiman di indonesia (the common urban pest ants in indonesia). Seminar Nasional Entomologi Indonesia (PEI) di Bali 23-25 Agustus 2007.

Hashimoto, Y., \& Rahman, H. (2003). Inventory \& collection: total protocol for understanding of biodiversity.
Hasriyanty, A. R., Buchori, D. (2015). Keanekaragaman semut dan pola keberadaannya pada daerah urban di Palu, Sulawesi Tengah. Jurnal Entomologi Indonesia,12(1), 39-47. Doi:10.5994/jei.12.1.39

Hutagalung, A. S. (1994). Condominium dan permasalahannya, suatu rangkuman materi perkuliahan. Jakarta: Elips Project FH UI

Latumahina, F.S., Ismanto, A. (2018). Pengaruh alih fungsi lahan terhadap keanekaragaman semut dalam hutan lindung nona-ambon. Prosiding Seminar Nasional VIII Biologi UNS, 177-181. Diakses dari https://jurnal.fkip.uns.ac.id

Odum, E.P. (1993). Dasar- Dasar Ekologi. Gajah Mada University Press. Yogyakarta.

Pielou, E. C. (1966). The Measurement of Diversity in Different Types of Biological Collections. Journal of Theoretical Biology, 13, 131-144. http://dx.doi.org/10.1016/00225193(66)90013-0

Yuniar, N., Haneda, N.F. (2015). Keanekaragaman semut (Hymenoptera: Formicidae) pada empat tipe ekosistem yang berbeda di Jambi.Pros Sem Nas Masy Biodiv Indon. 1

(7), 1584. 